\title{
FRANK WEDEKIND, PRECURSOR DO TEATRO ATUAL
}

\section{Erwin Theodor}

Faz exatamente setenta anos que Frank Wedekind escreveu sua peça "Rei Nicolò - Assim é a vida" (König Nicolo oder So ist das Leben) Figura central é uma rei destronado e banido, que espera poder representar no palco o papel de herói e soberano que a vida lhe negou. Mas quando, de cima do palco, classifica a "grande e séria tragédia" como a sua verdadeira vocação, provoca o riso dos espectadores, e, ao tentar revelar ao público as "profundezas de seu espírito", é aplaudido como cômico insuperável. Tôdas as suas expressões e frases são interpretadas como paródias e anedotas e todos os seus esforços por uma existência plácida e digna são fadados ao insucesso. Por fim, o rei usurpador contrata-o como bôbo da Côrte, e Nicoló, ao revelar ao antigo inimigo a sua verdadeira identidade, vê mais uma vez recusada a realidade em favor da aparência enganosa, já que a máscara lhe serve tão bem. E esta uma das formas pelas quais Wedekind provoca o riso e é assim que chega à concepção de sua tragédia, para a qual encontrou "novas formas de expressão, novos e profundos impulsos, ao tornar grotesco o dia-a-dia capitalista", no dizer de Georg Lukács, que ressalta ligar-se a rebeldia radical de Wedekind contra as formas mumificadas de vida burguesa a um "real vigor artístico de representação" (1)

Este inovador do teatro alemão, Frank (Benjamin Franklin) Wedekind, nasceu em 1864 em Hannover, tendo passado grande parte de sua juventude na Suíça (Aarau e Zurique), onde travou os primeiros contactos com autôres que mais tarde viriam a notabilizar-se, especialmente com Gerhart Hauptmann, Karl Henckell e Max Dauthendey. Sua existência inconstante levou-o por muitos lugares e funções as mais heterogêneas. Seu primeiro emprêgo de certa importância estabeleceu-o como encarregado de imprensa da Indústria Maggi, em 1886. Dois anos mais tarde veio a ser secretário do então conhecido circo Herzog; depois acompanhou o pintor e negociante em obras de arte Willy Grétor (que viria a ser o modêlo de seu Mar-

(1)) - LUKÃCS, Georg - Skizze einer Geschichte der neueren deutschen Literatur. Luchterhand, 1963, pp. 184/185 
quês von Keith e a quem é dedicado o "Espírito da Terra") à capital francesa, retornando pouco mais tarde à Suíça, como recitador, preocupado em difundir a obra de Henrik Ibsen. Em 1890 assina contratos como ator, dramaturgo e diretor em Lípsia e Munique, em 1896 vem a ser redator da revista satírica "Simplicissimus" e entre 1899 e 1900 passa um ano na cadeia, para expiar um crime de lesamajestade. Faleceu em 1918, em inícios daquêle ano que veria o fim da primeira Grande Guerra e extamente quando as suas obras começavam a superar os preconceitos do grande público, da crítica conservadora e da censura governamental.

Por vêzes Wedekind apresenta-se como um cínico, mas êste cinismo, apesar de genuíno, encobre um sêr extremamente susceptível, enquanto a expressão de seu sentimentalismo, muitas vêzes real, serve para mascarar o ceticismo mais profundo. Qundo pretendia apresentar-se como um boêmio, dava a impressão de um burguês à procura da boemia, e, quando se apresentava como burguês respeitável, a acatar as formas convencionais, parecia um indivíduo associal, fracassado. O próprio Wedekind desdenhava as suas apresentações cabaretísticas em circos e teatros de pouco categoria, assegurava que exercia essas atividades apenas por pura necessidade, para ganhar o necessário para o seu sustento. Mas sabemos que, como cantor de suas canções, era personalidade das mais marcantes. Assim escreveu Bertolt Brecht, que o viu e ouviu ainda poucas semanas antes de sua morte: "Há algumas semanas cantou na "Bonbonnière" as suas canções, acompanhando-se na guitarra, com voz áspera, um pouco monótona, e muito pouco escolada. Nunca cantor nenhum conseguiu entusiasmar-me nem comover-me tanto" Enquanto isto o próprio Wedekind perguntava: "E por que tenho eu de bancar o palhaço diante do público e rolar-me na sujeira?" Odiava o papel de artista circense que lhe era atribuído e sofria sob o seu pêso, talvez exatamente porque se adaptava tão bem ao seu caráter

A tônica constante do seu teatro é o protesto contra os aspectos enganosos da vida burguêsa e contra a dramaturgia naturalista. Nos dramas de Lulu, provàvelmente os mais importantes de sua obra $\mathrm{e}$ certamente aqueles aos quais dedicou mais tempo de elaboração (de 1892 a 1913), Wedekind enaltece a moral da amoralidade e a beleza física, mas também nas demais peças ou procedem suas personagens principais do mundo decadente, ou então apresentam-se como párias da sociedade, aventureiros, artistas de circo, prostitutas e homossexuais, a desenvolver um humor caricato, resultado do choque sofrido pelo moralista e idealista ao enfrentar a realidade da vida burguêsa no limiar do nosso século. Literàriamente as suas idéias (e a configuração das mesmas) atestam influências do movimento Sturm und 
Drang alemão, do romantismo, do teatro de Georg Büchner ( a forma aberta do teatro, a ironia e a linguagem gesticulante) e viriam a influenciar o expressionismo (pela estilização) e o drama de Bertolt Brecht (principalmente em virtude da inserção de modinhas populares, do recitativo baladesco e dos diálogos monolagados)

Entre os anos de 1892 e 1913 Wedekind dedicou-se à elaboração da 'tragédia' Lulu, inicialmente completando uma versão que ficou inédita, A Caixa de Pandora. Uma Tragédia Monstruosa do Ano de 1895 - (2), na qual já se encontra "in nuce" todo o material mais tarde empregado na tragédia. No próprio ano de 1895 foi publicada a tragédia $O$ Espírito da Terra - (3) - em quatro atos, à qual seguiu, em edições de 1902 e 1904, a Caixa de Pandora, em três atos, por sua vêz seguida da edição de Lulu, Tragédia em 5 Atos (1913), que se compõe dos atos I, II, e IV do Espírito da Terra e dos atos I e III da Caixa de Pandora.

Lulu é a personagem principal dos dois dramas. Os homens com que priva dão-lhe, entretanto, nomes os mais diversos. Por um é chamada Nelly, por outro Eva e por um terceiro Mignon. Não tem nome nem caráter definidos, assim como não sabe quem é seu pai ou sua mãe. Criança enjeitada, foi recolhida por um vagabundo (Schigo'ch), que, de acôrdo com as versões, é visto ora como seu amante e ora como seu pai e que a vende a Schön, único a quem ela amará e o qual, transcorridos vários anos, pretende dela desfazer-se, a fim de poder casar com a sua noiva burguesa.

Por intermédio de Schön, Lulu conhece o velho médico Goll, com quem se casa e que sôbre ela passa a exercer vigilância constante, iludida apenas uma vêz, momento que Lulu aproveita para entregar-se a Schwarz, o pintor. Quando Goll retorna ao estúdio de Schwarz e vê a espôsa nos braços do artista, sofre ataque apoplético, vindo a falecer sem que Lulu demonstre o menor traço de arrependimento. Casa depois com Schwarz, que mais tarde se suicidaria por constatar a impossibilidade de ser amado por Lulu. O próprio Schön vem a ser o terceiro marido, após desfeito o seu noivado. Quando Schön a encontra rodeada de diversos amantes, entre êles o seu próprio filho, o escritor e poeta Alwa e a condessa lésbica Geschwitz,

(2) - cf. Das Drama des Expressionismus (ed. Annalisa Viviani), Winkler, 1970, pp. 75 e seg. ROTHE Friedrich. - Frank Wedekinds Dramen. Metzler, 1968 classifica esta obra inédita como "A Caixa de Pandora, uma Tragédia Monstruosa", e acrescenta (fóra do título): do ano de 1895.

(3) - O título da tradução brasileira, aliás bastante insatisfatória, é Gnomo, ed. Selviço Doçumentação, MEC, 1961. 
procura levar Lulu ao suicídio, mas é esta quem o assassina. Assim conclui o Espírito da Terra. Os atos do drama, verdadeiras cenas paralelas, focam o problema da relação existente entre o instinto natural e as imposições sociais. Lulu personifica o impulso primitivo, o instinto sexual incontrolável, e encontra-se à procura de parceiro à sua altura. Esta procura estabelece o princípio compositório da peça: cada ato apresenta outro homem, cuja dependência maior ou menor de Lu'u é nitidamente caracterizada, e assim surge como que um feixe de ações dramáticas paralelas. O destino do médico Goll é idêntico ao de Schwarz, e no fundo também do dr. Schön, o que por sua vez é sublinhado pela identidade da estrutura cênica. Lulu sempre trai o marido atual com o próximo e ao fim de três dos quatro atos surge uma morte. Entretanto existe, apesar de tudo, um "crescendo continuo" na evolução da peça: a fôrça do adversário (ou do parceiro?) de Lulu parece aumentar constantemente, tanto assim que Goll morre vitimado por um ataque apoplético, Schwarz suicida-se e Cchön é assassinado. A tese unificadora é talvez a de que o eros, quando existente em todo o seu primitivismo, não pode ser suportado pelo burguês, educado e acostumado a uma falsa moral.

Na Caixa de Pandora, o segundo drama da Tragédia, surgem em três atos cenas sôltas, nas quais são apresentadas quase sempre as mesmas personagens. Aqui o eros é decadente e o seu desmoronamento é previsível madiante a demonstração da queda progressiva de Lulu.

Ela, que detinha em suas mãos o poder absoluto, será impelida até um ponto de impotência total perante a realidade do mundo em tôrno e. no momento que ela atinge o degrau mais baixo, vem a ser assassinada por Jack, o Estripador. A idéia do carrossel, a simbolizar a nossa vida, torna-se evidente quando, na cena final, em que Lulu é uma reles prostituta, quase reduzida a um animal rastejante, volta a ser focado o quadro, pintado por Schwarz no primeiro ato da primeira peça, a apresentá-la no momento de beleza mais radiante, e em costume de "pierrot" Esste quadro é uma espécie de "leitmotiv" da peça tôda. Logo depois de, no prólogo, o domador ter anunciado a cobra, o "animal real, o animal selvagem e belo", "criado para provocar desgraças, para atrair, seduzir, envenenar e matar", é trazida ao palco Lulu em suas vestes de "pierrot", e como tal surge lepois retratada por Schwarz. Apenas através desta máscara esta personificação dos instintos destruidores, do sexo impulsivo, mantém - sua constância. O pintor, que a apelida de "beleza infernal" com meias transparentes", submete-se a ela no momento em que comvleta o quadro, no primeiro ato. No segundo ato, a pintura adorna o slegante salão de Schwarz, enriquecido agora graças a artíficios en- 
gendrados por Schön, e depois dêste ter casado com Lulu, encontrase sôbre um "cavalete decorativo", adornado por uma "moldura de ouro antigo" O quadro desta beldade, ao mesmo tempo perigosamente atraente e curiosamente fantasiada, simboliza o destino dos homens que o seu modêlo submete à sua vontade. Os acontecimentos são reconhecidos em tôda a sua significação apenas se relacionados a êle, uma vez que não são motivados por circunstâncias concretas, mas sim combinados de tal forma que comprovem em um "crescendo" grotesco a fôrça destruidora do sexo.

Declarou Wedekind: "Com a minha Lulu no Espírito da Terra procurei esboçar um exemplar magnífico (Prachtexemplar) de mulher, tal como surge, quando um ser muito bem dotado pela natureza, mesmo que procedente das camadas mais baixas, consegue desenvol ver-se sem limites, rodeado por homens aos quais se impõe por sua inteligência muito mais aguda" - (4). O quadro representa perfeitamente tal intenção, e acresce que a figura do "pierrot" (já assim no famoso trabalho de Watteau) é muitas vêzes apresentada com expressão indizivelmente triste, revelando tanto nos traços fisionômicos quanto na vestimenta a mistura de aparência enganosa e miséria, de disfarces e franqueza. Lulu aparece por um lado natural e franca: "Eu disfarçar-me? Mas como tem essa idéia? - Nunca tive necessidade disto" Por outro lado parece estar contìnuamente a trocar os papéis, adaptando-os aos seus interlocutores: "Se eu não soubesse representar melhor do que se costuma representar no palco, o que teria sido de mim?" pergunta ela a certa altura, e Wilhelm Emrich, a quem devemos esta interpretação, observa: "Pois sim. Ela adapta-se a tudo e a todos e continua, apesar disso, sempre a mesma" Está aí exatamente a sua natureza, e talvez a explicação de sua amoralidade total ou sua moral distinta daquela que conhecemos: ela não se identifica com o papel que está a representar, porque não se fixa em nenhum tipo da sociedade, continuando sempre a ser a Lulu.

Na Caixa de Pandora o quadro desapareceu inicialmente, restando apenas o cavalete vazio. Mas, quando Lulu retorna da prisão, de onde fôra libertada pelo ardil da condessa homossexual, pergunta imediatamente: "E onde está o meu quadro?" Assim, êle lhe é trazido "empoeirado", conforme se diz, e colocado novamente no lugar anterior. Depois, no salão de jogo, onde o aventureiro CastiPiani, um indivíduo totalmente amoral, ao mesmo tempo agente policial e vendedor de escravas brancas, sugere vender Lulu a um pros-

(4) - EMRICH, Wilhelm - Wedekind. Die Lulu-Tragödie, in Das dertsche Drama II. Bagel, 1962, p. 214. 
tíbu'o egípcio, o quadro - agora adornado por estreita moldura dourada - como que observa as tentativas de fuga de Lulu, que veio a tornar-se, ela própria, uma vítima, submetida por seus instintos, e, no último ato, a Condessa Geschwitz, a única que continua a amá-la, leva-lhe o retrato, enrolado em um papel sujo, às águas-furtadas, onde Lulu e Alwa estão curtindo as agonias da fome e da miséria moral mais abjeta. Mediante alguns pregos tôscos é ali colocado numa parede. Contrastando com a miséria reinante, demonstra o desacôrdo existente entre os sonhos passados e a realidade de Lulu. Alwa compara o quadro à pessoa que ali se vende por alguns tostões aos mais míseros vagabundos, e diz: "A expressão infantil dos olhos, é, apesar de tudo que ela sofreu desde então, a mesma. Mas, e o orvalho fresco, que cobre tôda a pele, o sôpro perfumado de seus lábios, a luz radiante, que se espalhava da fronte branca e esta beleza provocante da carne juvenil no pescoço e nos braços " no que é interrompido pelo aventureiro Schigolch. "Isto tudo foi carregado pelo carro de lixo"

Vemos assim também por essa descrição de Alwa e Schigolch, que Lulu, vislumbrada ora como figura angelical e ora como "beldade diabólica" não pertence de fato a nenhuma das duas esferas. Aliás não pertence a esfera alguma. Atravessa todos os níveis da sociedade, sobe e cai por todos os degraus, não se fixa jamais. Falamos há pouco em "amoralidade", entretanto é forçoso refletirmos no conceito, antes de o aplicarmos aqui.

Não será, pelo contrário, Lulu a pretensão de uma exigência moral incondicional? Sua natureza instintiva, que não conhece condições ou submissões, corresponde a um determinado conceito moral. Assim, quando casada pela segunda vez (com o pintor Schwarz) Lulu revolta-se contra o fato de ser amada ùnicamente como animal e como fêmea:

\footnotetext{
"Ele sente-se seguro, por ter o contrato de casamento no bôlso. As preocupaçōes acabaram. Agora pode comportar-se e abandonar-se aos seus gostos, como se estivesse em casa (...) Êle é banal. Não tem educação. Não vê nada (...) é cego, cego,cego (...) Nada sou para êle além de fêmea e mais uma vez fêmea. Sinto-me envergonhada (...) Ele não conhece diferenças (...)"
}

Portanto impõe a exigência moral de ser amada como pessoa, como ser humano. Apenas assim 0 amor lhe parece suportável. Mas o que é a sua "individualidade"? Eis um problema insolúvel, porque não se encontra definição para esta característica tão pesso- 
al! Nem os liames legais e nem os costumes exercem a menor in fluência sôbre ela, po's as reformas burguesas lhe parecem fenômenos de decadência. Vê em redor adultérios e percebe que a esco'ha dos cônjuges depende muitas vêzes de interêsse financeiro, procedendo desta forma a situação trágica do conflito íntimo de Lulu da colis:̃o de exigências e valores absolutos com os valores relativos da sociedade em tôrno, mas que, ao contrário do que acontece na traoédia antiga, já não podem ser exatamente definidos. Diante do cadáver de seu primeiro marido Goll, desenvolve-se o seguinte diálogo entre Lulu e Schwarz:

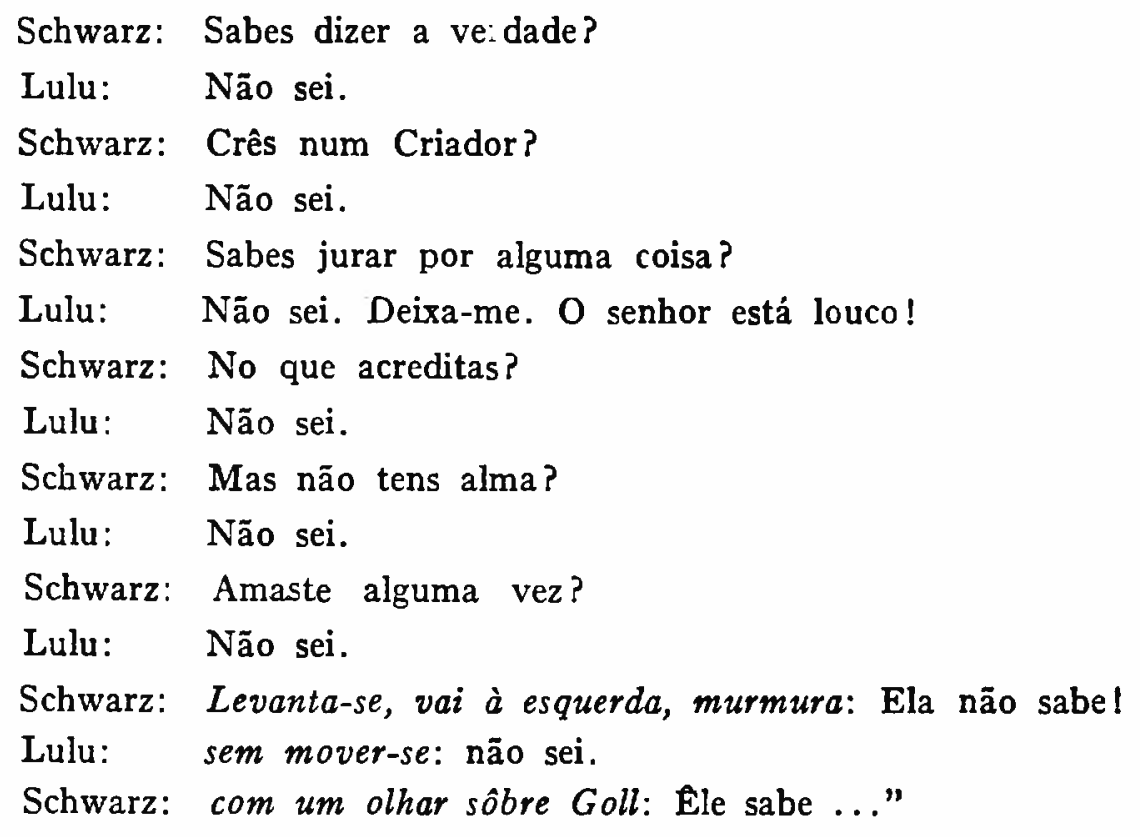

Portanto não existe nenhum va'or definido. O seu postu'ado moral não se prende a nenhuma fé e a nenhuma lei estabelecida, mas provém de sua natureza indefinível. Ela representa a liberdade suprema de instintos bio'ógicos, sem quaiquer freios, quer impostos pela educação, pela religião ou pelo meio em que vive. Sendo representante da nova moral, pregada por Wedekind, nada tem a ver com a realidade naturalista ou psicológica. A própria intenção de Wedekind ao estruturá-la nẽo é muito clara, e os dois dramas são permeados de torpezas, de exagêros, de cenas horripilantes, assim como, por outro lado, de alusões literárias (talvez o próprio títu'o do Espírito da Terra seja uma alusão ao Fausto, àquele espírito de que o sábio medieval pretende aproximar-se, mas que - no fundo - não consegue compreender) e de reminiscência de estudos psicológicos. $\mathrm{Na}$ investigação literária alemã, a figura de Lulu foi submetida a interpretações as mais diversas: Paul Fechter considerou-a "a mulher na sua forma primitiva" Kutscher falou da "personificação de 
uma fôrça elementar", para Diebold, Lulu era o pseudônimo da "força mística", de acôrdo com Milkereit tratava-se da representante da "natureza pura", Emrich desenvolveu a idéia da moral de Lulu, oposta à imoralidade das hipocrisiais sociais, mas parece indiscutível que, tal como seus modelos mitológicos Helena e Pandora, Lulu une os males e o pó da terra com uma beleza celestial. Tal como Pandora, constituída de água e terra, Lulu traz doença e morte, mas ao mesmo tempo permite vislumbrar, tal como aconteceu a Fausto ao contemplar Helena no espelho, uma beleza radiante, que não parece terrena, capaz de satisfazer os sonhos de todos os homens. Assim, cada nôvo amante procura completar a própria personalidade com traços característicos de Lulu, esperando realizar-se. E por isto que ela assume uma forma diferente no conceito de cada um: como anjo e como diabo, como amante e como infiel, espiritualizada e brutal. Para o aventureiro Schigolch, que a encontrou quando pequena, ela é sempre Lulu - (5);. Dr. Goll conferiu-lhe, até mesmo no contrato de casamento, o nome de Nelly, para o Dr. Schön e Alwa ela é Mignon, a misteriosa figura de Wilhe to Schwarz apelida-a de "Eva", comtemplando-a, portanto, como a mulher primitiva e completa.

Os exageros grotescos a assinalar os encontros de Lulu com o seu ambiente pertencem à ambivalência do cômico e trágico, inerente à sua própria figura. Ela atravessa todos os momentos da vida, sem que as experiências venham a determinar, através de recordação ou de "lições aprendidas", o seu comportamento. Apenas uma vez, naquela passagem em que se queixa do segundo marido, ressurge um momento anterior: "Muitas vêzes sonho ainda com Goll" diz Lulu, e continua: "Ele está aqui, como se nunca tivesse ido embora. Mas anda só de meias. Ele não está zangado comigo. Apenas terrívelmente triste. E depois tem mêdo, como se estivesse aqui sem permissão po'icial. De resto sente-se bem em nossa companhia. Só não consegue perceber porque venho josando tanto dinheiro pela janela. "Ao que Schön respondeu:: Você tem saudade é do chicote!" Mas, de resto, cada ato em si parece desligado do anterior, e a irrelevância do sentimento diante de atos, devidos exc'usivamente aos instintos, é comprovada cênicamente. Surge uma espécie de desconfiança da fôrça intelectual da palavra, que faz com que o diálogo não se mova livremente, mas seja impelido pelo jôgo de cena. A morte dos três maridos nada significa para Lu'u, que diz, à vista do cadáver do médico: "Acabou a dança. remédios já não lhe adiantam, e eu sou rica agora" O triunfo do cinismo une-se à vontade de

(5) - Só na versão de 1895 ( O Espirito da Terra) Schigolch apelida-a 
sobrevivência e surge assim o horror, grotescamente expresso, e aliado ao absurdo, gerando uma comicidade bem do gôsto de autores dramáticos modernos, do tipo Ionesco ou Dürrenmatt. Depois do suicídio do pintor, Lulu percebe que as mãos de Schön estão manchadas de sangue e dispõe-se a limpá-las. Schön diz: "E o sangue do teu marido", obtendo a seguinte resposta: "Não deixa manchas" Mais tarde Lulu retruca à declaração de amor de Alwa, filho de Schön, "Envenenei a tua mãe", e Alwa parece aceitar tudo o que aconteceu, ao dizer finalmente: "A espôsa do artista tornou-se depois mulher do meu defunto pai; a mulher de meu pai tornou-se a minha amante. E assim o correr do mundo, quem poderia opôr-se?" As palavras perdem-se no vazio e não nos podemos furtar à constatação de que aqui o impulso vital não pode ser estacado por acontecimento nehum e que, pelo contrário, as mortes parecem até servirlhe de estimulante, até o momento em que a própria figura vital, representada por esta mulher, que não conhece paralelo na história do teatro, é morta na ocasião de sua mais abjecta decadência pelo "estripador" Trata-se, sem dúvida, de uma visão grotesca de vitalidade insaciável, estranha a si mesma e incapaz de se compreender. Daí a constante de sua resposta "não sei" no trecho já referido e daí também o pouco valor de suas palavras, desprovidas de significação real. Assim, ela diz a Schwarz, o pintor de seu quadro, que "nunca amara antes de conhecê-lo", a Schön, que êle "era o único" que jamais amou e, logo em seguida ao filho dêste, Alwa: "Ser-te-ei fiel tôda a minha vida. Só quero pertencer a ti." As suas palavras são tão desprovidas de va!or quanto as mortes dos seus maridos e servem explìcitamente para realçar a falta de lógica, inerente aos enígmas existenciais, que desespera aquêles que procuram sempre uma solução clara e insofismável para os seus problemas. No último ato do Espírito da Terra procura Schön agarrar os seus rivais, escondidos desde o momento de sua entrada em cena, e surge uma caçada burlesca na galeria, atrás das cortinas, junto à lareira, até que o próprio filho Alwa leve o marido enciumado ao desespêro. A cena final da Caixa de Pandora adquire caráter semelhante quando os indivíduos desclassificados, que Lulu recolhe da rua, se evidenciam como verdadeiras figuras caricatas a representar a depravação e a miséria humanas.

Os dois dramas são concebidos como "tragédias", conforme o atesta a própria designação dada pelo Autor Mas rea!mente é forçoso reconhecer que a conceituação do "trágico" tem de ser reformulada, para abranger essas duas peças. Richard Hamann incluiu o Espírito da Terra há sessenta-e-cinco anos no seu conceito da "forma impressionista": 
"Da maneira mais espirituosa é a forma [impressionista] desenvolv'da no Espírito da Terra de Wedekind, que tècnicamente é sem dúvida o drama mais interessante da literatura moderna. Em cada ato rea'iza-se a mesma ação. Personagem principal é uma mulher, mas não um herói trágico, e sim triunfante, o destino, que em cada ato destrói um homem. O médico Goll, um velho gozador, sofre um ataque de coraç̃o perante o espetáculo que se lhe oferece no estúdio, onde deixou sua mulher com o artista, a fim de que ela fôsse retratada. Este artista suicida-se quando se lhe abrem os olhos sôbre o passado e o presente desta sua mulher. No terceiro ato, um príncipe, que é africanista, é amigàvelmente pôsto de lado e no último ato o marido, que durante tôda a peça fốra o amante dessa mulher, é morto a tiros por ela própria, quando, enganado por ela com meia dúzia de amantes, procura forçá-la a dar cabo da própria vida. A peça corresponde também ao estilo mais moderno da arte dramática, ao apresentar uma aç $\%$ desinteressante num estilo impossível, apenas esboçadamente parodístico, no intuito de ilustrar um tema e descrever um tipo. E o tema da mulher que nada mais quer do homem a partir do momento que o subjugou. A peça inteira repete o tema de cada ato individual ao tornar o Dr. Schön, que já é o amante dessa mulher no primeiro ato, marido apenas no seu derradeiro. E um tipo, o Espírito da Terra, espécie moderna do "eterno feminino", muda de homens como troca de vestido. Em cada ato êsse "Espírito da Terra" tem outro nome e depois de cada catástrofe muda de roupa. O fim é musical e não dramático. A reunião burlesca de tôda uma galeria de amantes presos, entre os quais um aluno de ginásio e uma condessa-pintora, corresponde a um acôrdo final, ressonante com tímbales e trombones. Tudo poderia continuar da mesma maneira, mas chega, porque já nos cansamos." (6).

E realmente situa-se essa "tragédia" tão próxima da peça burlesca, que Wedekind agradeceu em uma carta ao Diretor Georg Stollberg: "Antes de mais nada achei todos os quatro atos invulgarmente coloridos, vivos e divertidos" (7) A personagem de Lulu não é jamais sèriamente ameaçada nesta primeira peça; ela personifica de fato sempre o mesmo princípio do prazer. Se, entretanto, considerarmos as duas peças como constituindo um complexo, a Tragédia Lulu, Obra Dramática em Duas Partes, tal como firam apresentadas a partir da segunda edição (1903) poderemos chegar a propor um nôvo conceito do "Trágico", a adaptar-se ao drama de Wedekind.

(6) - HAMANN, Richard - Der Impressionismus. Köln, 1907, pp. 76 e seg.

(7) - Georg Stollberg, aluno de Otto Brahm em Berlim, foi diretor do Schauspielhaus de Munich, durante muito tempo o teatro principal da capital bávara. 
Tal como na tragédia antiga surge o embate, a colisão de valôres opostos, mas êsses valôres, ao contrário do que antigamente acontecia, não são universalmente reconhecidos e subtraem-se, por assim dizer, a uma definição. Não têm caráter uniforme e não são absolutos, sendo exatamente por isso que, para o Autor, os defensores de valôres absolutos têm de acabar no crime ou na loucura, tal como aconteceu com o Rei Nicolò.

Lulu triunfou sôbre os homens no Espírito da Terra, mas na Caixa de Pandora Goll, Schwarz e Schön encontram o seu vingador em Jack, o Estripador. O caráter irrefreável de Lulu leva-a à ilegalidade e começa a sua queda física e moral. Da sua beleza antes irresistível, resta apenas "a expressão infantil" dos olhos e, simbòlicamente, é ela descrita na sua primeira entrada em cena na Caixa de Pandora, como "descendo as escadas com dificuldade, apoiada no braço de Schigolch" Se no segundo ato ela ainda rejeita terminantemente a idéia de vender-se, chega a aceitar no terceiro ato a prostituição e mesmo a encontrar prazer nessa última fase de sua existência. A indicação mais evidente de sua decadência física é a exclamação com que rejeita no terceiro ato a imagem do seu retrato, com o qual ainda no primeiro se comprazia em comprar e quando Schigolch comenta: "Quem hoje a agarra, não pode ter idéia do que ela foi na nossa juventude" ela perde definitivamente a aura de beleza eterna. Fenecendo a figura de Lulu, ela passa a ser uma mulher mortal como as demais e o próprio título do segundo drama adquire assim uma nova idéia. Não é Lulu a proprietária da Caixa de Pandora mas sim a própria, com cuja eliminação o estripador presta um benefício à humanidade.

Wedekind torna-se, desta maneira, precursor decidido do drama moderno e as modificações do caráter trágico correspondem à verificação da experiência nova do nosso mundo. Se Dürrenmatt, na sua Visita da Velha Senhora, apresenta não a luta em favor da justiça e sim o processo de compra dessa justiça, se Beckett em $\vec{A}$ Espera de Godot apresenta figuras para as quais já não existe evolução, que vivem à beira de um abismo invisível sem entender as vozes que dêle se levantam, demonstrando as suas palavras, intermináveis e desprovidas de senso, a falta de sentido de tôdas as tentativas de expressão, empreende também Wedekind a eliminação de qualquer fixação conceitual e a inversão total dos valôres anteriormente aceitos. A tragédia em Lulu, assim como em tantos outros dramas mais modernos é, por assim dizer, a decomposição da própria tragédia. Já que tôdas as tragédias se desenrolam além de tôdas as palavras, não pode mais ser escrita a obra que reflete a vida. Alwa, 
escritor e filho do Dr. Schön, percebe esta verdade, e em vez de escrever o seu drama quer vivê-lo. Wedekind é Alwa e procura demonstrar a antinomia existente entre a palavra imaginada e a vida experimentada. Assim transporta o seu drama ao mundo de hoje, e se êste mundo surge de maneira grotesca é porque, no dizer de Dürrenmatt, "o nosso mundo leva da mesma maneira ao grotesco quanto levou à bomba atômica' $\mathrm{O}$ grotesco é exclusivamente expressão, um paradoxo sensual, a forma, ou melhor: a 'não forma', o rosto de um mundo sem rosto"

Wedekind envereda por aquilo que a concepção tradicional do teatro classificaria de "caminho anti-teatral", mas faz assim surgir uma visão grotesca da nossa realidade, que é a sua maneira de torná-la transparente (8)

(8) - Entre a bibliografia a respeito de Frank Wedekind, cumpre ressaltar:

EMRICH, Wilhelm - "Wedekind. Die Lulu - Tragödie", in: Das Deutsche Drama vom Barock bis zur Gegenwart. Ed. Benno von Wiese, vol. II, Düsseldorf, $19602^{\text {z }}$ Edição, pp. 207-228.

FAESI, Robert - "Ein Vorläufer: Frank Wedekind" in: Expressionismus. Ed. H. Friedmann e O. Mann. Heidelberg, 1956 pp. 241-263.

KAUFMANN, Hans - "Zwei Dramatiker: Gerhart Hauptmann und Frank Wedekind" in: Krisen und Wandlungen dir deutschen Literatur von Wedekind bis Feuchtwanger. BerlinWeimar, 1966 - pp. 45-81.

KUTSCHER, A tur - Wedekind, Leben und Werk. Zum hundertsten Geburtstag des Dichters bearbeitet und neu herausgegeben von Karl Ude. München, 1964.

MICHELSEN, Peter - "Frank Wedekind" in: Deutsche Dichter der Moderne. Ed. Benno von Wiese, Berlin, - 1965, pp. 49-67.

ROTHE, Friedrich - Frank Wedekinds Dramen.. Jugendstil und Lebensphilosophie, Stuttgart, 1969.

VöLKER, Klaus - Frank Wedekind. Velbert, 1965. 